NASA

Technical Memorandum 105396
AVSCOM

Technical Report 91-C-045

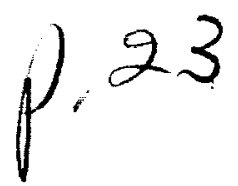

\title{
Elevated Temperature Axial and Torsional Fatigue Behavior of Haynes 188
}

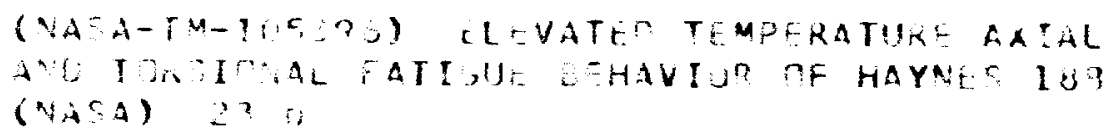

Uncliss

$03 / 30 \quad 0104034$

Peter J. Bonacuse

Propulsion Directorate

U.S. Army Aviation Systems Command

Lewis Research Center

Cleveland, Ohio

and

Sreeramesh Kalluri

Sverdrup Technology, Inc.

Lewis Research Center Group

Brook Park, Ohio

June 1992 
- $\cdots$ 


\title{
ELEVATED TEMPERATURE AXIAL AND TORSIONAL FATIGUE
}

\section{BEHAVIOR OF HAYNES 188}

\author{
Peter J. Bonacuse \\ Propulsion Directorate \\ U.S. Army Aviation Systems Command \\ Lewis Research Center \\ Cleveland, Ohio 44135 \\ and \\ Sreeramesh Kalluri \\ Sverdrup Technology, Inc. \\ Lewis Research Center Group \\ Brook Park, Ohio 44142
}

\section{SUMMARY}

The results of high-temperature axial and torsional low-cycle fatigue experiments performed on Haynes 188, a wrought cobalt-base superalloy, are reported. Fatigue tests were performed at $760^{\circ} \mathrm{C}$ in air on thin-walled tubular specimens at various strain ranges and under strain control. Data are also presented for coefficient of thermal expansion, elastic modulus, and shear modulus at various temperatures from room to $1000^{\circ} \mathrm{C}$, and monotonic and cyclic stress-strain curves in tension and in shear at $760^{\circ} \mathrm{C}$.

This data set is used to evaluate several multiaxial fatigue life models (most were originally developed for room temperature multiaxial life prediction) including von Mises equivalent strain range (ASME boiler and pressure vessel code), Manson-Halford, Modified Multiaxiality Factor (proposed in this paper), Modified Smith-Watson-Topper, and Fatemi-Socie-Kurath. At von Mises equivalent strain ranges (the torsional strain range divided by $\sqrt{3}$, taking the Poisson's ratio to be 0.5 ), torsionally strained specimens lasted, on average, factors of 2 to 3 times longer than axially strained specimens. The Modified Multiaxiality Factor approach shows promise as a useful method of estimating torsional fatigue life from axial fatigue data at high temperatures.

Several difficulties arose with the specimen geometry and extensometry used in these experiments. Cracking at extensometer probe indentations was a problem at smaller strain ranges. Also, as the largest axial and torsional strain range fatigue tests neared completion, a small amount of specimen buckling was observed.

\section{INTRODUCTION}

In high-temperature environments it is rare to find an actual working component that is subjected to a purely uniaxial stress or strain field. Typically, when a structure is exposed to an external heat source, the heated portion expands while portions of the structure that are farther from the heat source, and cooler, constrain this expansion. In many cases a thermal gradient in a structure induces biaxial stress fields. The stresses resulting from "self-constraint" can also be amplified by external constraints on the structure. These thermally induced stresses are often accompanied by mechanical loads (e.g., centrifugal and pressure loads on a gas turbine blade) 
that have a different magnitude and direction than the thermal stresses. An added complexity is introduced when the thermal loads and the mechanical loads are not imposed simultaneously. This can cause the magnitudes and the directions of the maximum principal stresses and strains to change continuously during each loading cycle. Synergistic and previously undiscovered damage mechanisms may arise under these complicated loading conditions.

Haynes 188 was chosen as a model material for this study because it is often used in aeronautical and space-based, high thermal-shock applications: in LOX (liquid oxygen) posts in the space shuttle main engine, in combustors for the T800 turboshaft engine, and in other structures that are subjected to large thermal transients in oxidizing environments.

In this program, monotonic and cyclic axial and torsional tests were conducted on Haynes 188 at $760{ }^{\circ} \mathrm{C}$. Several multiaxial fatigue life prediction models were examined for their applicability to Haynes 188 at this temperature. These models include the von Mises equivalent strain range approach (ASME boiler and pressure vessel code, case 1592-7, 1975); a method originally developed by Manson and Halford (ref. 1); the Modified Multiaxiality Factor approach described in this report; the Modified Smith-Watson-Topper parameter (refs. 2 and 3); and a multiaxial fatigue life model developed by Fatemi, Socie, and Kurath (refs. 4 and 5). The Fatemi-Socie-Kurath model is actually a correlation for this data set in that it requires both axial and torsional fatigue data to determine all of the model constants.

\section{SYMBOLS}

\begin{tabular}{|c|c|}
\hline $\mathrm{B}, \mathrm{C}$ & coefficients of axial elastic and plastic life relations \\
\hline $\mathrm{B}^{\prime}, \mathrm{C}^{\prime}$ & $\begin{array}{l}\text { coefficients of elastic and plastic life relations in Modified Multiaxiality Factor } \\
\text { approach }\end{array}$ \\
\hline$B_{t}, C_{t}$ & coefficients of torsional elastic and plastic life relations \\
\hline b,c & exponents of axial elastic and plastic life relations \\
\hline$b_{t}, c_{t}$ & exponents of torsional elastic and plastic life relations \\
\hline $\mathrm{E}, \mathrm{G}$ & Young's and shear moduli \\
\hline $\mathbf{K}, \mathbf{K}^{\prime}$ & monotonic and cyclic axial strength coefficients \\
\hline $\mathbf{K}_{\mathrm{t}}, \mathbf{K}_{\mathbf{t}}^{\prime}$ & monotonic and cyclic torsional strength coefficients \\
\hline k & constant in Fatemi-Socie-Kurath parameter \\
\hline $\mathrm{MF}, \mathrm{TF}$ & multiaxiality and triaxiality factors \\
\hline $\mathbf{N}_{\mathrm{T}}$ & transition life \\
\hline$N_{f}$ & cyclic life \\
\hline $\mathrm{n}, \mathbf{n}^{\prime}$ & monotonic and cyclic axial strain-hardening exponents \\
\hline $\mathrm{n}_{\mathrm{t}}, \mathrm{n}_{\mathrm{t}}^{\prime}$ & monotonic and cyclic torsional strain-hardening exponents \\
\hline$\alpha$ & coefficient of thermal expansion \\
\hline$\gamma, \epsilon$ & engineering shear and axial strain amplitudes \\
\hline$\gamma_{\mathbf{e}}, \gamma_{\mathbf{p}}$ & elastic and plastic engineering shear-strain amplitudes \\
\hline
\end{tabular}




$\begin{array}{ll}\gamma_{\max } & \text { maximum engineering shear strain } \\ \gamma_{\mathrm{xy}}, \gamma_{\mathrm{yz}}, \gamma_{\mathrm{zx}} & \text { orthogonal engineering shear strains } \\ \Delta & \text { range of the variable } \\ \epsilon_{\mathrm{T}} & \text { transition strain amplitude } \\ \varepsilon_{\mathrm{e}}, \varepsilon_{\mathrm{p}} & \text { elastic and plastic strain amplitudes } \\ \varepsilon_{\mathrm{eq}} & \text { von Mises equivalent strain amplitude } \\ \epsilon_{\mathrm{xx}}, \epsilon_{\mathrm{yy}}, \varepsilon_{\mathrm{zz}} & \text { orthogonal normal strains } \\ \varepsilon_{\mathrm{f}}^{\prime} & \text { axial fatigue ductility coeflicient } \\ \varepsilon_{1} & \text { maximum principal strain } \\ \nu & \text { Poisson's ratio } \\ \nu_{\mathrm{e}}, \nu_{\mathrm{p}} & \text { elastic and plastic Poisson's ratios } \\ \sigma_{,}, \tau & \text { axial and shear stress amplitudes } \\ \sigma_{\mathrm{eq}} & \text { von Mises equivalent stress amplitude } \\ \sigma_{\mathrm{f}}^{\prime} & \text { axial fatigue strength coefficient } \\ \sigma_{\mathrm{o}}, \tau_{\mathrm{o}} & \text { mean axial and shear stresses } \\ \sigma_{\mathrm{y}} & \text { axial yield strength } \\ \sigma_{\mathrm{xx}}, \sigma_{\mathrm{yy}}, \sigma_{\mathrm{zz}} & \text { orthogonal normal stresses } \\ \sigma_{\mathrm{n}}^{\max } & \text { maximum normal stress on the maximum shear strain plane } \\ \sigma_{1}^{\max } & \text { maximum normal stress on the maximum principal strain plane } \\ \sigma_{1}, \sigma_{2}, \sigma_{3} & \text { principal stresses } \\ \tau_{\mathrm{xy}}, \tau_{\mathrm{yz}}, \tau_{\mathrm{zx}} & \text { orthogonal shear stresses } \\ \end{array}$

\section{EXPERIMENTAL DETAILS}

\section{Material and Specimens}

Haynes alloy 188, 50.8-mm o.d., round bar stock that was hot rolled, centerless ground, and solution annealed was purchased from a commercial vendor. Table I shows the chemical composition of the alloy. Thin-walled tubular fatigue specimens (fig. 1) were machined from the bar stock. The bores of the specimens were finished in a honing operation to help bias fatigue crack initiation to the outer surface of the tubular specimen (fatigue crack initiation from the internal surface was observed in a previous, room-temperature study (ref. 6)). All specimens in this program had final failure cracks that initiated at the outer surfaces.

\section{Test Apparatus}

All tests were performed on a single servohydraulic axial-torsional test system under computer control. A commercially available axial-torsional extensometer equipped with quartz 
probes was used in all tests for strain measurement and control. Two indentations were pressed into the outer surface of the specimen with a precision fixture (developed at NASA Lewis Research Center) so that the conical tips of the extensometer probes could be mounted. A $50-\mathrm{kW}$ induction heating system coupled to a movable three-coil heating fixture (ref. 7) was used to heat the fatigue specimens to the test temperature (fig. 2). This arrangement permitted the adjustment of the heat input distribution, and thus allowed the thermal gradient within the gage section of each specimen to be kept to a minimum at any test temperature. Further details on the testing hardware and the computer test control and data acquisition system can be found in references 6 and 8 .

\section{YOUNG'S MODULUS, SHEAR MODULUS, AND COEFFICIENT OF THERMAL EXPANSION}

The variations of Young's modulus (E) and the shear modulus (G) with temperature were determined by using a single specimen. Axial and torsional load excursions were performed at various temperatures starting at room temperature and progressing to $1000^{\circ} \mathrm{C}$ in increments of $100^{\circ} \mathrm{C}$. The specimen was instrumented with thermocouples spot welded at 16 locations (fig. 3 ) to monitor the temperature profile. Except for the highest control temperatures (900 and $1000{ }^{\circ} \mathrm{C}$ ), the temperature at each thermocouple within the gage section was maintained to within 1 percent of the temperature (absolute) at the control thermocouple. The most deviant of the measured temperatures within the gage section at the 900 and $1000{ }^{\circ} \mathrm{C}$ test temperatures were higher by 1.25 and 2 percent of the control thermocouple temperatures, respectively. A fully reversed cycle in load control with a frequency of $0.1 \mathrm{~Hz}$ was used, and the peak loads were kept to 25 percent of the handbook value for the yield strength at each temperature tested. Least squares linear fits of the recorded load and strain data were then performed to determine the Young's and shear moduli. Figure 4 presents these test results and the second-degree polynomial least squares fits to the Young's and shear moduli versus temperature data. This figure also contains handbook values for the dynamic elastic modulus of Haynes 188 (ref. 9). The experimental values obtained in this study closely agree with the handbook values except at the highest temperatures where the measured values were low, probably because of the slightly higher temperatures in the gage section.

In the process of measuring the elastic properties, the axial thermal strain was measured by the extensometer and recorded. These data were used to calculate the value of the mean coefficient of thermal expansion $(\alpha)$, with room temperature as a reference, for each increment in temperature. Figure 5 shows a plot of these data and the second-order polynomial fit to the data.

\section{AXIAL AND TORSIONAL TESTS}

Haynes 188 exhibits a ductility minimum at $760{ }^{\circ} \mathrm{C}$ (ref. 9). Since low-cycle fatigue life is governed by the strain range and the material's ductility, this temperature was selected to characterize the axial and torsional behavior of this material. 


\section{Monotonic Axial and Torsional Stress-Strain Behavior}

Tensile and monotonic torsional tests were performed at $760^{\circ} \mathrm{C}$ to obtain the following: monotonic axial and torsional stress-strain curves; yield strengths in tension and in shear; ultimate tensile strength; and percent reduction in area (\%RA) for Haynes 188 using the axialtorsional test configuration previously described. These tests were performed with the same thin-walled tubular specimen design as that used in the fatigue tests. In the tensile test a simple axial excursion was performed under strain control at a constant strain rate of $0.0008 \mathrm{sec}^{-1}$ (chosen to approximate the strain rate in the axial fatigue tests) to 4-percent axial strain. The specimen was then unloaded to zero; the extensometer was removed; and the specimen was reloaded in stroke control to complete separation. A stroke rate was chosen that would impart a strain rate roughly equivalent to that used in the strain-controlled segment.

The 0.2-percent offset yield and ultimate tensile strengths of the axially loaded specimen were 268 and $490 \mathrm{MPa}$, respectively. The area of the fractured surface of this specimen was measured to determine the tensile ductility. The \%RA was 55.1, giving a tensile ductility of 0.801. The temperature profile of the specimen degraded as the specimen elongated and was pulled out of the induction heating coils. This could have introduced some error in the values of the ultimate tensile strength, the \%RA, and the calculated tensile ductility.

A monotonic torsion test was performed to obtain the monotonic shear stress/strain behavior and the torsional yield stress of Haynes 188 at $760^{\circ} \mathrm{C}$. This test was performed in shear strain control with a shear strain rate of $0.0006 \mathrm{sec}^{-1}$ (again, chosen to approximate the torsional fatigue test strain rates) to 3-percent torsional strain. The 0.2 -percent offset torsional yield strength was $163 \mathrm{MPa}$. This test was not taken to failure for several reasons: (1) a commonly accepted monotonic torsional failure definition was not available; (2) the tube probably would have buckled before a shear crack could have formed; and (3) a monotonic shear failure could require hundreds of percent shear strain. Furthermore, if the test were actually taken to failure, the load frame used in this program would require that the specimen be ungripped and regripped many times (maximum rotation range is $100^{\circ}$ ) to put the required shear strain into the specimen.

Ramberg-Osgood type stress-strain relations were used to characterize the stress and strain data collected in these experiments:

$$
\begin{array}{cc}
\varepsilon=\frac{\sigma}{\mathrm{E}}+\left[\frac{\sigma}{\mathrm{K}}\right]^{1 / \mathrm{n}} & \text { for monotonic axial test } \\
\text { or } \\
\gamma=\frac{\tau}{\mathrm{G}}+\left[\frac{\tau}{\mathrm{K}_{\mathrm{t}}}\right]^{1 / \mathrm{n}_{\mathrm{t}}} \text { for monotonic torsional test }
\end{array}
$$

The strain-hardening exponents and the strength coefficients were determined by fitting lines to the logarithms of the stress amplitudes versus the logarithms of the plastic strain amplitudes using least squares. The calculated values of $K$ and $n$ for the monotonic axial stress-strain 
curve were $512 \mathrm{MPa}$ and 0.093 , respectively. The calculated values of $K_{t}$ and $n_{t}$ for the monotonic torsional stress-strain curve were $264 \mathrm{MPa}$ and 0.083 , respectively.

\section{Cyclic Axial and Torsional Stress-Strain Behavior}

Cyclic axial and torsional fatigue tests were conducted in air on Haynes 188 at $760{ }^{\circ} \mathrm{C}$. Triangular waveforms with a frequency of $0.1 \mathrm{~Hz}$ were used in both cases. The midlife (stabilized) stress amplitudes are plotted against the imposed strain amplitudes in figures 6 and 7 for the axial and torsional tests, respectively. Ramberg-Osgood type relations were used to characterize the axial and torsional cyclic stress-strain data:

$$
\begin{aligned}
& \varepsilon=\frac{\sigma}{\mathrm{E}}+\left[\frac{\sigma}{\mathrm{K}^{\prime}}\right]^{1 / \mathrm{n}^{\prime}} \text { for axial fatigue tests } \\
& \gamma=\frac{\tau}{\mathrm{G}}+\left[\frac{\tau}{\mathrm{K}_{\mathrm{t}}^{\prime}}\right]^{1 / \mathrm{n}_{\mathrm{t}}^{\prime}} \text { for torsional fatigue tests }
\end{aligned}
$$

The values of $K^{\prime}$ and $n^{\prime}$, obtained by least squares analysis as described above, for the axial cyclic stress-strain curve were $891 \mathrm{MPa}$ and 0.113 . The values of $K_{t}^{\prime}$ and $n_{t}^{\prime}$, again obtained by least squares analysis, for the torsional cyclic stress-strain curve were $589 \mathrm{MPa}$ and 0.142 , respectively.

The monotonic axial and torsional stress-strain material response, obtained in the previously described experiments, are also plotted in these figures. Note that Haynes 188 exhibits considerable cyclic hardening in fully reversed loading at $760^{\circ} \mathrm{C}$ in both the axial and torsional fatigue tests. Leese and Morrow (ref. 10) used a similar method to characterize the room temperature, cyclic, torsional stress-strain behavior for 1045 steel.

\section{Comparison of Equivalent Stress-Strain Curves (Axial Versus Torsional)}

A traditional approach using von Mises equivalent strains and stresses was adopted to directly compare the torsional experiments with the axial experiments:

$$
\begin{aligned}
& \varepsilon_{\mathrm{eq}}=\frac{1}{\sqrt{2}(1+\nu)}\left[\left(\varepsilon_{\mathrm{xx}}-\varepsilon_{\mathrm{yy}}\right)^{2}+\left(\varepsilon_{\mathrm{yy}}-\varepsilon_{\mathrm{zz}}\right)^{2}+\left(\varepsilon_{\mathrm{zz}}-\varepsilon_{\mathrm{xx}}\right)^{2}+\frac{3}{2}\left(\gamma_{\mathrm{xy}}^{2}+\gamma_{\mathrm{yz}}^{2}+\gamma_{\mathrm{zx}}^{2}\right)\right]^{1 / 2} \\
& \sigma_{\mathrm{eq}}=\frac{1}{\sqrt{2}}\left[\left(\sigma_{\mathrm{xx}}-\sigma_{\mathrm{yy}}\right)^{2}+\left(\sigma_{\mathrm{yy}}-\sigma_{\mathrm{zz}}\right)^{2}+\left(\sigma_{\mathrm{zz}}-\sigma_{\mathrm{xx}}\right)^{2}+6\left(\tau_{\mathrm{xy}}^{2}+\tau_{\mathrm{yz}}^{2}+\tau_{\mathrm{zx}}^{2}\right)\right]^{1 / 2}
\end{aligned}
$$


For pure torsion, with the Poisson's ratio $\nu$, assumed to be 0.5 (plastic strain-dominated, constant-volume assumption), the values of the equivalent strain and stress reduce to the following:

$$
\varepsilon_{\mathrm{eq}}=\frac{\gamma}{\sqrt{3}} ; \quad \sigma_{\mathrm{eq}}=\sqrt{3} \tau
$$

Figure 8 displays the von Mises equivalent torsional strain amplitude versus the von Mises equivalent stabilized torsional stress amplitude. A comparison of this curve with the axial cyclic stress-strain curve (also shown in fig. 8) indicates that the material exhibits more cyclic hardening under torsional loading than is predicted by the von Mises criterion.

\section{FATIGUE TESTS}

The failure definition used for these experiments was a 10-percent dropoff in the peak axial or torsional loads. The testing software stores the peak load values in a cycle at logarithmic intervals. These stored peak load values are used as a reference to compare with peak load values from subsequent cycles. The 10-percent load dropoff corresponded to surface crack lengths of 3 to $14 \mathrm{~mm}$ in the axial fatigue tests (except the largest strain amplitude test which had a crack of $40 \mathrm{~mm}$ ) and surface crack lengths of 8 to $26 \mathrm{~mm}$ in the torsional fatigue tests.

\section{Fatigue Data}

Tables II and III contain stress and strain range values of the near half-life hysteresis loops of the axial and torsional fatigue tests. These tables also include the final crack lengths (measured after the tests were completed). The extensometer probe indentations caused a problem in some of the specimens. These indentations were necessary to positively locate the extensometer probes on the specimen. In the longer life (lower strain range) tests, the crack that caused failure of the specimen occurred at an indentation. Fatigue data corresponding to the specimens that failed as a result of a crack at an extensometer indentation were excluded from the computation of the axial and torsional strain-life relations. In all tests the main crack followed a path perpendicular to the maximum principal stress direction.

\section{Axial Fatigue Life Relations}

The elastic and plastic strain ranges versus fatigue life data for the axial fatigue tests are presented in figure 9. Data points corresponding to specimens that failed as a result of a crack at the extensometer indentation are indicated with solid symbols. The elastic strain range was calculated for each test by using the measured Young's modulus and the recorded stress range. This value was then subtracted from the measured total strain range for that test to obtain the plastic strain range. Log-log fits were performed, excluding the data corresponding to the specimens that cracked at the indentations (solid symbols), on the calculated elastic and plastic strain ranges versus fatigue life. The calculated elastic, plastic, and total life relations are also presented in figure 9. The form of the axial strain-life equation is shown in equation (5). 


$$
\begin{aligned}
\Delta \varepsilon & =\mathrm{B}\left(\mathrm{N}_{\mathrm{f}}\right)^{\mathrm{b}}+\mathrm{C}\left(\mathrm{N}_{\mathrm{f}}\right)^{\mathrm{c}} \\
& =0.00913\left(\mathrm{~N}_{\mathrm{f}}\right)^{-0.0823}+0.590\left(\mathrm{~N}_{\mathrm{f}}\right)^{-0.730}
\end{aligned}
$$

\title{
Torsional Fatigue Life Relations
}

For the torsional fatigue data, similar calculations were performed to separate the elastic and plastic engineering shear strain ranges. Log-log fits of the elastic and plastic engineering shear strain ranges versus fatigue life were performed. Figure 10 shows the elastic and plastic engineering shear strain range data and the corresponding life relationships. As with the axial fatigue data, data points corresponding to specimens with extensometer indentation cracking are indicated with solid symbols and were omitted from the computation of the torsional life relations. The torsional fatigue life relation is represented by the following:

$$
\begin{aligned}
\Delta \gamma & =B_{t}\left(N_{f}\right)^{b_{t}}+C_{t}\left(N_{f}\right)^{c_{t}} \\
& =0.0184\left(N_{f}\right)^{-0.100}+2.17\left(N_{f}\right)^{-0.715}
\end{aligned}
$$

Leese and Morrow (ref. 10) adopted a similar method to obtain the torsional fatigue life relations for 1045 steel at room temperature.

\begin{abstract}
ANALYSIS
Several multiaxial fatigue life prediction parameters (refs. 1 to 5) were selected to correlate the high-temperature torsional fatigue life data for Haynes 188 at $760^{\circ} \mathrm{C}$. All of these parameters, developed mainly to model room temperature multiaxial fatigue life behavior, require at least a uniaxial fatigue life data base to determine the respective model constants. Also, all fatigue life models examined cannot be solved in closed form for the fatigue life. An iterative solution is usually required. Results of the axial and torsional fatigue tests were used to derive the constants for multiaxial life prediction models and to gage the applicability of these models to Haynes 188 at elevated temperatures.
\end{abstract}

\section{von Mises Equivalent Strain Range Parameter}

This parameter uses the von Mises equivalent strain range (eqs. (3) and (4)) taken from plasticity theory. For the torsional fatigue tests, the equivalent strain range is twice the equivalent strain amplitude computed using equation (4). This equivalent strain range is then used on the left hand side of the axial strain-life relation (eq. (5)) to predict the torsional fatigue lives. As shown in figure 11, this model underpredicts the torsional fatigue life by a factor of 2 to 3. The von Mises equivalent strain range equation for Haynes 188 at $760^{\circ} \mathrm{C}$ is as follows: 


$$
\Delta \epsilon_{\mathrm{eq}}=0.00913\left(\mathrm{~N}_{\mathrm{f}}\right)^{-0.0823}+0.590\left(\mathrm{~N}_{\mathrm{f}}\right)^{-0.730}
$$

\section{Manson-Halford Parameter}

Manson and Halford (ref. 1) proposed a parameter that modifies the von Mises equivalent plastic strain range by a stress-based multiaxiality factor which, in turn, is based on the triaxiality factor proposed by Davis and Connelly (ref. 11). The equivalent plastic strain range for the torsional fatigue tests is twice the result of substituting only the plastic engineering shear strain amplitude into equation (4). The equivalent plastic strain range, modified by the multiaxiality factor, is then used in conjunction with the axial plastic life relationship to estimate the torsional fatigue life. The Manson-Halford parameter accounts for the change in the ductility of a material as the state of stress changes. This parameter for Haynes 188 at $760^{\circ} \mathrm{C}$ is as follows:

$$
\operatorname{MF}\left(\Delta \varepsilon_{p}\right)_{e q}=C\left(N_{f}\right)^{c}=0.590\left(N_{f}\right)^{-0.730}
$$

where

and

$$
\begin{gathered}
\mathrm{MF}=\frac{1}{2-\mathrm{TF}} ; \mathrm{TF} \leq 1 \\
\mathrm{MF}=\mathrm{TF} ; \mathrm{TF} \geq 1 \\
\mathrm{TF}=\frac{\sigma_{1}+\sigma_{2}+\sigma_{3}}{\frac{1}{\sqrt{2}} \sqrt{\left(\sigma_{1}-\sigma_{2}\right)^{2}+\left(\sigma_{2}-\sigma_{3}\right)^{2}+\left(\sigma_{3}-\sigma_{1}\right)^{2}}}
\end{gathered}
$$

In torsion the triaxiality factor $(\mathrm{TF})$ is zero $\left(\sigma_{1}=-\sigma_{2}\right.$, and $\left.\sigma_{3}=0\right)$ therefore, the multiaxiality factor (MF) is $1 / 2$. This parameter works fairly well in the very low-cycle regime but is overly conservative as the amount of plastic strain decreases (fig. 12). A total strain range version of the Manson-Halford parameter, the Modified Multiaxiality Factor approach, (eq. (9)) has been developed by the authors to correct for this shortcoming.

\section{Modified Multiaxiality Factor Approach}

The functional form for this approach (eq. (9)) is obtained by employing the following assumptions. First, the hydrostatic stress (the triaxiality factor, and hence, the multiaxiality factor, is a measure of the hydrostatic stress) has a much larger effect on the axial plastic life line than the axial elastic life line, so that the multiaxiality factor is used to shift only the axial plastic life line as proposed by Manson and Halford (ref. 1). Second, the axial elastic life relation is subsequently translated horizontally to preserve the cyclic axial stress-strain curve under different states of multiaxial stress. Details of the development of equation (9) are presented in the appendix. The form of the equation and the constants for torsional fatigue are as follows: 


$$
\begin{aligned}
\operatorname{MF}(\Delta \varepsilon)_{\text {eq }} & =M^{(1-b / c)} B\left(N_{f}\right)^{b}+C\left(N_{f}\right)^{c} \\
& =0.00494\left(N_{f}\right)^{-0.0823}+0.590\left(N_{f}\right)^{-0.730}
\end{aligned}
$$

Figure 13 shows a plot of this equation with the torsional fatigue data. This equation predicts the low- and the high-engineering shear strain range data equally well.

\section{Modified Smith-Watson-Topper Parameter}

The conventions for the following two multiaxial fatigue life models are different from those used in the previously discussed models. The Modified Smith-Watson-Topper and Fatemi-SocieKurath models represent fatigue life in reversals-to-failure $\left(2 N_{f}\right)$ and express stresses and strains as amplitudes instead of ranges.

The Modified Smith-Watson-Topper parameter has been recommended by Socie (ref. 3) for materials that exhibit an early transition to a tensile transgranular mode of failure. Originally presented in reference 2 as a mean stress parameter, it was subsequently modified by Socie (ref. 3) to model multiaxial fatigue life behavior.

$$
\begin{aligned}
\frac{\Delta \varepsilon_{1}}{2} \sigma_{1}^{\max } & =\sigma_{\mathrm{f}}^{\prime} \varepsilon_{\mathrm{f}}^{\prime}\left(2 \mathrm{~N}_{\mathrm{f}}\right)^{\mathrm{b}+\mathrm{c}}+\frac{\sigma_{\mathrm{f}}^{\prime 2}}{\mathrm{E}}\left(2 \mathrm{~N}_{\mathrm{f}}\right)^{2 \mathrm{~b}} \\
& =403\left(2 \mathrm{~N}_{\mathrm{f}}\right)^{-0.812}+3.98\left(2 \mathrm{~N}_{\mathrm{f}}\right)^{-0.165}
\end{aligned}
$$

The exponents $b$ and $c$ are the same as the axial elastic and plastic line exponents for the fatigue life models previously discussed. The constants $\varepsilon_{\mathrm{f}}^{\prime}$ and $\sigma_{\mathrm{f}}^{\prime}$ are derived from the uniaxial fatigue data set. This fatigue life model along with the torsional fatigue data is depicted in figure 14. The Smith-Watson-Topper parameter does not model the torsional fatigue behavior of Haynes 188 very well. For the majority of the life range covered in this program, this model overpredicted the fatigue life by up to a factor of 6 . This observation indicates that the Modified Smith-Watson-Topper model (at least for Haynes 188 at $760^{\circ} \mathrm{C}$ ) is unsuitable for conservative design practice.

\section{Fatemi-Socie-Kurath Parameter}

The Fatemi-Socie-Kurath parameter (refs. 4 and 5) is included in this paper for future reference (eq. (11)). For torsional fatigue tests, it is not a predictor of fatigue life as much as a correlator in that the torsional fatigue data are necessary to determine one of the constants $(k)$. The method used to determine the parameter $\mathrm{k}$ from axial and torsional fatigue data is described in reference 5. The value of $k$ derived from this data set is 1.0 in the life regime of interest. Figure 15 shows a plot of the Fatemi-Socie-Kurath parameter values versus reversalsto-failure for the axial and torsional fatigue tests. In using the maximum shear strain as the 
dominant parameter, this model recognizes that the mode of crack initiation in most metals occurs by persistent slip in preferentially oriented surface grains.

$$
\begin{aligned}
\gamma_{\max }\left(1+\frac{\sigma_{\mathrm{n}}^{\max }}{\sigma_{\mathrm{y}}}\right)=\left(1+\nu_{\mathrm{e}}\right) \frac{\sigma_{\mathrm{f}}^{\prime}}{\mathrm{E}}\left(2 \mathrm{~N}_{\mathrm{f}}\right)^{\mathrm{b}}+\frac{\mathrm{k}}{2}\left(1+\nu_{\mathrm{e}}\right) \frac{\sigma_{\mathrm{f}}^{\prime 2}}{\mathrm{E} \sigma_{\mathrm{y}}}\left(2 \mathrm{~N}_{\mathrm{f}}\right)^{2 \mathrm{~b}} \\
+\left(1+\nu_{\mathrm{p}}\right) \varepsilon_{\mathrm{f}}^{\prime}\left(2 \mathrm{~N}_{\mathrm{f}}\right)^{\mathrm{c}}+\frac{\mathrm{k}}{2}\left(1+\nu_{\mathrm{p}}\right) \varepsilon_{\mathrm{f}}^{\prime} \frac{\sigma_{\mathrm{f}}^{\prime}}{\sigma_{\mathrm{y}}}\left(2 \mathrm{~N}_{\mathrm{f}}\right)^{\mathrm{b}+\mathrm{c}} \\
=0.00638\left(2 \mathrm{~N}_{\mathrm{f}}\right)^{-0.0823}+0.00880\left(2 \mathrm{~N}_{\mathrm{f}}\right)^{-0.165} \\
+0.734\left(2 \mathrm{~N}_{\mathrm{f}}\right)^{-0.730}+1.011\left(2 \mathrm{~N}_{\mathrm{f}}\right)^{-0.812}
\end{aligned}
$$

This model successfully correlated the axial and torsional fatigue data.

\section{DISCUSSION}

Several of the axial and torsional lower strain range fatigue tests developed cracks at indentations placed in the specimen surface for the extensometer probes. These indentations were necessary to ensure accurate mounting of the probes and to prevent movement relative to the surface over the course of a test. The precision indentation fixture allowed accurate control of the depth of penetration into the specimen's outer surface. The indentation depth was kept to the minimum necessary to prevent the probes from sliding at the maximum displacements expected in a given test. In pressing the indentations, residual stress fields are induced around the indentations. In the longer life tests these residual stress fields may relax to the point where they no longer prevent the stress concentration at the indentation from initiating a crack. Several specimen design alternatives that involve removing material from the gage section between the extensometer indentations are under consideration. Such a modification to the specimen design should force the crack initiation site into this reduced gage section. Elastoplastic finite element analysis and experimental techniques could be used to account for the extra plastic strain that would occur in the reduced gage section. Cracking at the extensometer probe indentations has been observed only in the experiments performed on Haynes 188 at $760{ }^{\circ} \mathrm{C}$. No such cracking was observed in previously conducted room temperature axialtorsional fatigue tests of similar strain ranges and performed on 304 and 316 stainless steels (refs. 6 and 12). These observations indicate that Haynes 188 at $760^{\circ} \mathrm{C}$ is more notch sensitive than the previously tested stainless steels.

At the highest axial and torsional strain ranges, the specimens exhibited small amounts of buckling. Fortunately, the specimen started buckling after the formation of a macroscale crack. To prevent buckling in future high strain range testing, a thicker-walled specimen will probably be necessary. The practical axial and torsional strain range limits for the specimen geometry used in this study are approximately 2.5 and 4.3 percent, respectively. 
Among the multiaxial fatigue life prediction models examined in this study, the Modified Multiaxiality Factor approach provided good estimations of the torsional fatigue lives from uniaxial fatigue data. In particular, this approach eliminated the conservative predictions of the torsional fatigue lives by the Manson-Halford parameter at small strain ranges. In view of the fact that the main cracks followed paths that were perpendicular to the maximum principal stress direction in all fatigue tests, the reasons for the unconservative predictions of the torsional fatigue lives by the Modified Smith-Watson-Topper parameter are not clear at this time. As previously stated, even though it may be nearly as accurate as the Modified Multiaxiality Factor approach, the Fatemi-Socie-Kurath parameter requires torsional fatigue data to obtain one of its constants.

\section{CONCLUSION}

The described fatigue test system configuration and multiaxial data acquisition and control software have been used to perform axial and torsional tests on Haynes 188 at high temperatures.

The multiaxial life models evaluated in this study estimate the torsional fatigue lives to varying degrees of accuracy. The von Mises equivalent strain range parameter was conservative by up to a factor of 3 whereas the Modified Smith-Watson-Topper parameter was unconservative by up to a factor of 6 . The predictions by the Manson and Halford method were within a factor of 2 at larger strain ranges; however, at lower strain ranges they were conservative by up to a factor of 5. The Modified Multiaxiality Factor approach proposed in this paper rectified this problem and predicted all the torsional fatigue lives to within a factor of 2 . The method of Fatemi, Socie, and Kurath correlated the axial and torsional fatigue data to within a factor of 2.5.

A modification to the specimen geometry may be necessary to avoid indentation cracking at lower strain ranges. Also, the small amounts of buckling that were observed at the higher strain ranges might be eliminated by adopting a specimen design with a thicker wall. 
APPENDIX-DEVELOPMENT OF THE TOTAL EQUIVALENT STRAIN RANGE

VERSION OF THE MULTIAXIALITY FACTOR APPROACH

In low-cycle fatigue, under fully reversed uniaxial loading conditions, the Basquin and Manson-Coffin equations

$$
\begin{aligned}
& \Delta \varepsilon_{\mathrm{e}}=\mathrm{B}\left(\mathrm{N}_{\mathrm{f}}\right)^{\mathrm{b}} \\
& \Delta \varepsilon_{\mathrm{p}}=\mathrm{C}\left(\mathrm{N}_{\mathrm{f}}\right)^{\mathrm{c}}
\end{aligned}
$$

adequately describe the fatigue life behavior of many engineering alloys.

The total strain-life relation is obtained by adding the Basquin and Manson-Coffin equations (fig. 16).

$$
\begin{aligned}
\Delta \varepsilon & =\Delta \varepsilon_{\mathrm{e}}+\Delta \varepsilon_{\mathrm{p}} \\
& =\mathrm{B}\left(\mathrm{N}_{\mathrm{f}}\right)^{\mathrm{b}}+\mathrm{C}\left(\mathrm{N}_{\mathrm{f}}\right)^{\mathrm{c}}
\end{aligned}
$$

At the transition life, $N_{\mathrm{T}}$, where $\Delta \varepsilon_{\mathrm{e}}=\Delta \varepsilon_{\mathrm{p}}$, the transition strain range, $\Delta \varepsilon_{\mathrm{T}}$, is given by

$$
\Delta \varepsilon_{\mathrm{T}}=\mathrm{B}\left(\mathrm{N}_{\mathrm{T}}\right)^{\mathrm{b}}=\mathrm{C}\left(\mathrm{N}_{\mathrm{T}}\right)^{\mathrm{c}}
$$

Solving equation (A4) for the transition life, $\mathrm{N}_{\mathrm{T}}$, results in

$$
N_{T}=\left[\frac{C}{B}\right]^{1 /(b-c)}
$$

Substituting equation (A5) into equation (A4) and solving for the transition strain range, one obtains 


$$
\Delta \varepsilon_{T}=C\left[\frac{C}{B}\right]^{c /(b-c)}
$$

Manson and Halford (ref. 1) reasoned that under multiaxial loading conditions, the fatigue life of a material would be different from that under a uniaxial loading condition because multiaxiality can alter the ductility. Hence, they proposed that the von Mises equivalent plastic strain range be multiplied by a multiaxiality factor to account for the change in the ductility under multiaxial loading conditions. Their multiaxiality factor is a measure of hydrostatic stress and is based on the triaxiality factor of Davis and Connelly (ref. 11). Thus, equation (A2) under multiaxial loading becomes

$$
\operatorname{MF}\left(\Delta \varepsilon_{\mathrm{p}}\right)_{\mathrm{eq}}=\mathrm{C}\left(\mathrm{N}_{\mathrm{f}}\right)^{\mathrm{c}}
$$

or

$$
\left(\Delta \varepsilon_{\mathrm{p}}\right)_{\mathrm{eq}}=\frac{\mathrm{C}}{\mathrm{MF}}\left(\mathrm{N}_{\mathrm{f}}\right)^{\mathrm{c}}
$$

This equation deals only with the plastic portion of the von Mises equivalent strain range. In order to extend this approach to the total von Mises equivalent strain range, we propose that the following form of life relation be used for life prediction under multiaxial loading:

$$
(\Delta \varepsilon)_{\mathrm{eq}}=\mathrm{B}^{\prime}\left(\mathrm{N}_{\mathrm{f}}\right)^{\mathrm{b}}+\mathrm{C}^{\prime}\left(\mathrm{N}_{\mathrm{f}}\right)^{\mathrm{c}}
$$

From equation (A8),

$$
\mathrm{C}^{\prime}=\frac{\mathrm{C}}{\mathrm{MF}}
$$

This implies that the plastic life line is moved down for $M F>1$ (e.g., biaxial tension) and is moved up for $M F<1$ (e.g., torsion). The new plastic life line is shown in figure 16 for MF $>1$. The value of $B^{\prime}$ in equation (A9) can be obtained by assuming that the cyclic stressstrain curve remains unchanged during multiaxial loading. It follows from this assumption that the transition strain range also remains unchanged. While this assumption may not be valid for all multiaxial loading conditions, it is at least consistent in that it uses both the uniaxial fatigue life relation and the corresponding cyclic stress-strain curve. The calculation of $B^{\prime}$ is accomplished by translating the elastic life line horizontally such that the transition strain range 
(eq. (A6)) remains the same. This method is analogous to the treatment of elastic and plastic life lines under different mean stress conditions by Manson and Halford (ref. 13).

Thus,

$$
\Delta \varepsilon_{\mathrm{T}}^{\prime}=\mathrm{C}^{\prime}\left[\frac{\mathrm{C}^{\prime}}{\mathrm{B}^{\prime}}\right]^{\mathrm{c} /(\mathrm{b}-\mathrm{c})}=\mathrm{C}\left[\frac{\mathrm{C}}{\mathrm{B}}\right]^{\mathrm{c} /(\mathrm{b}-\mathrm{c})}=\Delta \varepsilon_{\mathrm{T}}
$$

Substituting equation (A10) into equation (A11) and solving for $B^{\prime}$ yields

$$
\mathrm{B}^{\prime}=\mathrm{MF}^{-\mathrm{b} / \mathrm{c}} \mathrm{B}
$$

Substituting equation (A10) and equation (A12), equation (A9) becomes

$$
(\Delta \varepsilon)_{\mathrm{eq}}=\mathrm{MF}^{-\mathrm{b} / \mathrm{c}} \mathrm{B}\left(\mathrm{N}_{\mathrm{f}}\right)^{\mathrm{b}}+\frac{\mathrm{C}}{\mathrm{MF}}\left(\mathrm{N}_{\mathrm{f}}\right)^{\mathrm{c}}
$$

Multiplying both sides of equation (A13) by MF, the Modified Multiaxiality Factor equation is obtained:

$$
\mathrm{MF}(\Delta \varepsilon)_{\mathrm{eq}}=\mathrm{MF}^{(1-\mathrm{b} / \mathrm{c})} \mathrm{B}\left(\mathrm{N}_{\mathrm{f}}\right)^{\mathrm{b}}+\mathrm{C}\left(\mathrm{N}_{\mathrm{f}}\right)^{\mathrm{c}}
$$

Equations (A13) and (A14) constitute the basis of the Modified Multiaxiality Factor approach. 


\section{REFERENCES}

1. Manson, S.S., et al.: Multiaxial Low Cycle Fatigue of Type 304 Stainless Steel. Discussion. J. Eng. Mater. Technol., vol. 99, no. 3, 1977, pp. 283-286.

2. Smith, K.N.; Watson, P.; and Topper, T.H.: A Stress-Strain Function for the Fatigue of Metals. J. Mater., vol. 5, no. 4, Dec. 1970, pp. 767-778.

3. Socie, D.F.: Multiaxial Fatigue Damage Models. J. Eng. Mater. Technol., vol. 109, no. 4, 1987, pp. 293-298.

4. Fatemi, A.; and Socie, D.F.: A Critical Plane Approach to Multiaxial Fatigue Damage Including Out-of-Phase Loading. Fatigue Fract. Eng. Mater. Struct., vol. 11, no. 3, 1988, pp. 149-165.

5. Fatemi, A.; and Kurath P.: Multiaxial Fatigue Life Predictions Under the Influence of Mean-Stresses. J. Eng. Mater. Technol., vol. 110, Oct. 1988, pp. 380-388.

6. Bonacuse, P.J.; and Kalluri, S.: Results of Inphase Axial-Torsional Fatigue Experiments on 304 Stainless Steel. NASA TM-101464, 1989.

7. Ellis, J.R.; and Bartolotta, P.A.: Adjustable Induction-Heating Coil. NASA Tech Brief, vol. 14 , no. 11 , Nov. 1990 , p. 50.

8. Kalluri, S.; and Bonacuse, P.J.: A Data Acquisition and Control Program for AxialTorsional Fatigue Testing. Applications of Automation Technology to Fatigue and Fracture Testing, A.A. Braun, N.E. Ashbaugh, and F.M. Smith, eds., ASTM STP 1092, American Society for Testing and Materials, Philadelphia, 1990, pp. 269-287.

9. Nickel Base Alloys. International Nickel Company, Inc., New York, 1977.

10. Leese, G.E.; and Morrow, J.: Low Cycle Fatigue Properties of a 1045 Steel in Torsion, Multiaxial Fatigue. ASTM STP 853, K.J. Miller and M.W. Brown, eds., American Society for Testing and Materials, Philadelphia, 1985, pp. 482-496.

11. Davis, E.A.; and Connelly, F.M.: Stress Distribution and Plastic Deformation in Rotating Cylinders of Strain-Hardening Material. J. Appl. Mech., vol. 81, 1959, pp. 25-30.

12. Bonacuse, P.J.; and Kalluri, S.: Axial-Torsional Fatigue: A Study of Tubular Specimen Thickness Effects. NASA TM-103637, 1990.

13. Manson, S.S.; and Halford, G.R.: Correction: Practical Implementation of the Double Linear Damage Rule and Damage Curve Approach for Treating Cumulative Fatigue Damage. Int. J. Fract., vol. 17, no. 4, Aug. 1981, pp. R35-R42. 
TABLE I.-CHEMICAL

COMPOSITION OF

\begin{tabular}{|l|c|}
\hline \multicolumn{2}{|c|}{ HAYNES 188} \\
\hline \multicolumn{1}{|c|}{ Element } & Weight, \\
percent
\end{tabular}

TABLE II.-AXIAL FATIGUE DATA FOR HAYNES 188 AT $760^{\circ} \mathrm{C}$

\begin{tabular}{|c|c|c|c|c|c|c|c|}
\hline Specimen & $\Delta c_{\text {. }}$ & $\Delta \epsilon_{\mathrm{P}}$ & $\Delta \varepsilon$ & $\begin{array}{c}\Delta \sigma \\
\mathrm{MPa}\end{array}$ & $\begin{array}{c}\sigma_{0^{\prime}} \\
\mathrm{MPa}\end{array}$ & $N_{f}$ & $\begin{array}{c}\text { Final crack } \\
\text { length, } \\
\text { mm }\end{array}$ \\
\hline HY 42 & 0.00635 & 0.02150 & 0.02784 & 1066 & -5.30 & 94 & $>40$ \\
\hline HY 34 & .00540 & .00566 & .01106 & 934 & -6.17 & 625 & 6 \\
\hline HY 32 & .00482 & .00287 & .00768 & 832 & -.70 & 1420 & 14 \\
\hline HY 39 & .00466 & .00135 & .00600 & 786 & -2.11 & 3654 & 8 \\
\hline HY 25 & .00415 & .00047 & .00462 & 702 & -.53 & 19157 & 7 \\
\hline HY 44 & .00394 & .00024 & .00416 & 658 & 4.93 & 35106 & 4.5 \\
\hline $\mathrm{HY}_{43^{\circ}}$ & .00368 & & .00368 & 627 & 3.51 & 193474 & $3-4$ \\
\hline
\end{tabular}

Indentation cracking-data not included in computing axial fatigue life relation.

TABLE III.-TORSIONAL FATIGUE DATA FOR HAYNES 188 AT $760^{\circ} \mathrm{C}$

\begin{tabular}{|l|c|c|c|c|c|r|r|r|}
\hline Specimen & $\Delta \gamma_{e}$ & $\Delta \gamma_{\mathrm{p}}$ & $\Delta \gamma$ & $\Delta \varepsilon_{\text {eq }}$ & $\begin{array}{c}\Delta \tau, \\
\mathrm{MPa}\end{array}$ & $\begin{array}{c}r_{\text {eq }} \\
\mathrm{MPa}\end{array}$ & $\mathrm{N}_{\mathrm{f}}$ & $\begin{array}{c}\text { Final } \\
\text { crack } \\
\text { length, } \\
\text { rnm }\end{array}$ \\
\hline HY8 & 0.01032 & 0.03868 & 0.04900 & 0.02829 & 667 & 1.74 & 259 & $>20$ \\
HY6 & .00969 & .01948 & .02917 & .01684 & 621 & 1.89 & 984 & 13 \\
HY2 & .00844 & .01122 & .01966 & .01135 & 536 & 1.59 & 2194 & 13 \\
HY5 & .00799 & .00515 & .01314 & .00759 & 533 & 1.74 & 2268 & 22 \\
HY7 & .00779 & .00542 & .01321 & .00763 & 504 & 2.04 & 4933 & 26 \\
HY3 & .00717 & .00255 & .00972 & .00561 & 455 & 1.74 & 18043 & 26 \\
HY4 & .00616 & .00111 & .00727 & .00420 & 397 & 1.90 & 157774 & 8 \\
\hline
\end{tabular}

andentation cracking-data not included in computing torsional fatigue life reiation. 


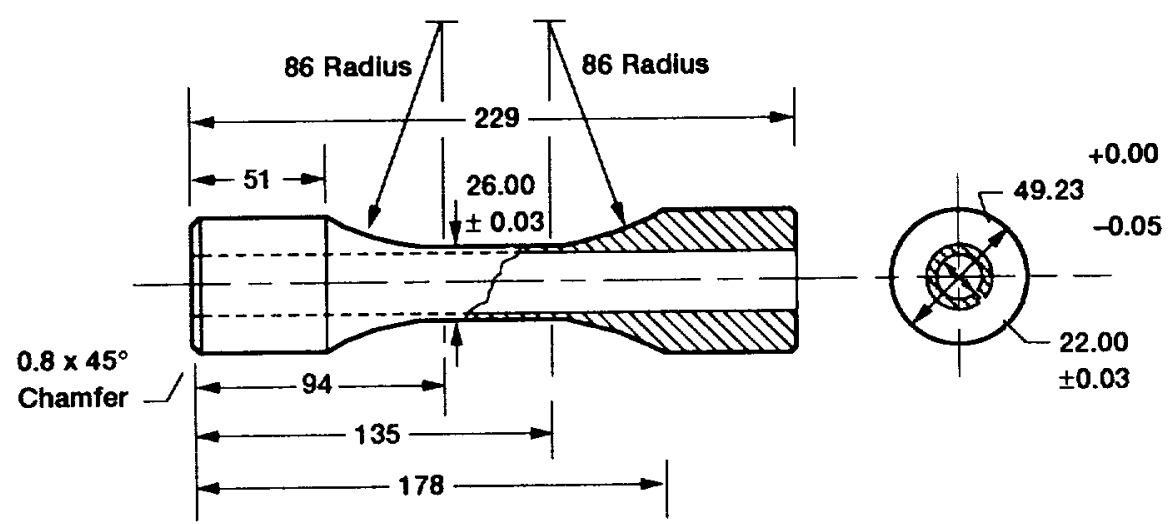

Figure 1.-Thin-walled tubular axial-torsional fatigue specimen. (All dimensions are in millimeters.)

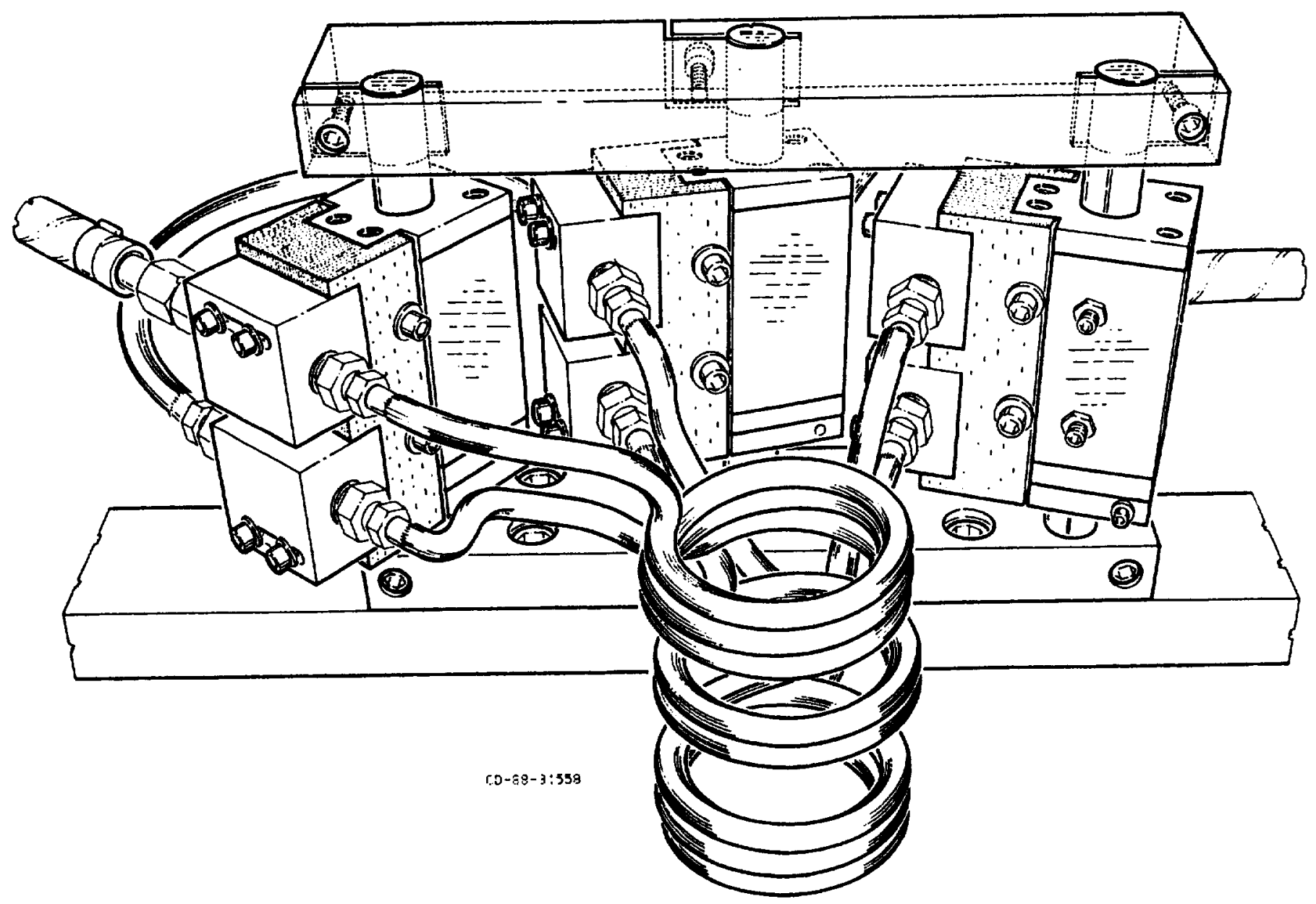

Flgure 2.-Schematic of Induction heating fixture. 


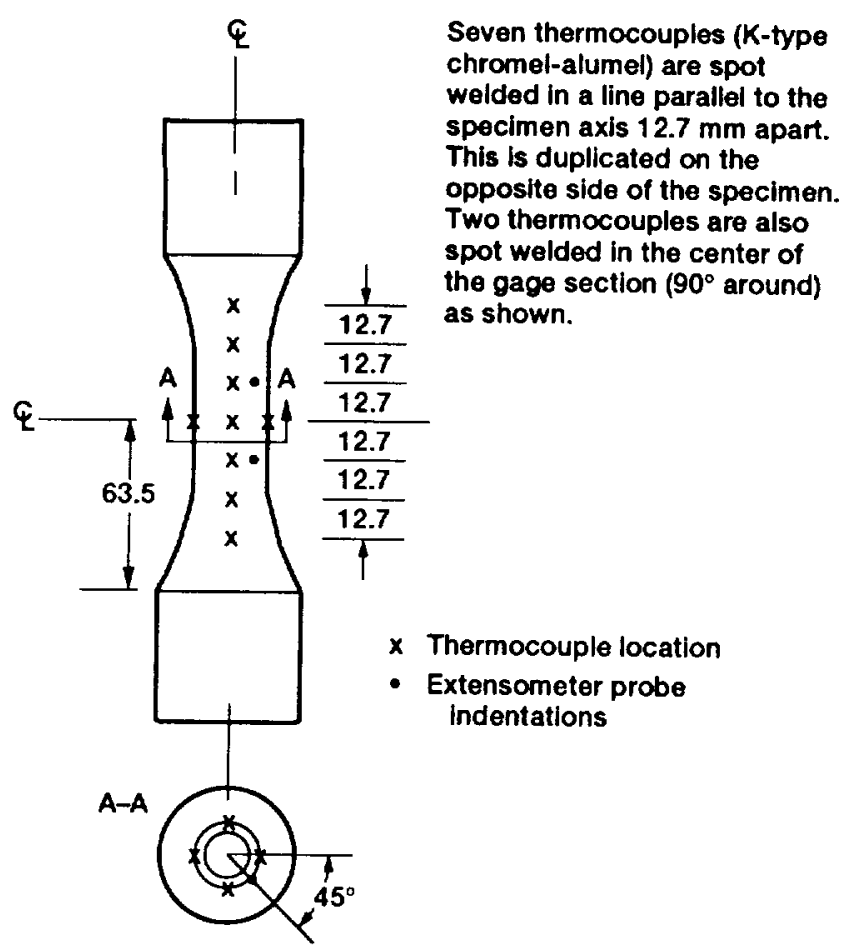

Figure 3.-Thermocouple layout for measuring the temperature gradient in the tubular specimen. (All dimensions are in millimeters.)

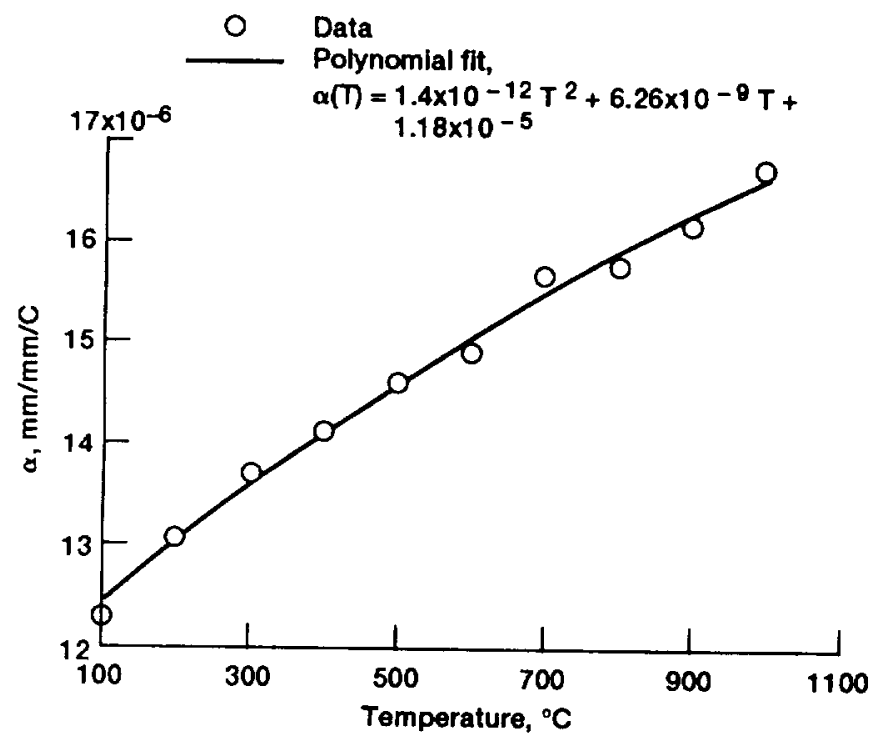

Figure 5.-Measured value of the thermal expansion coefficient versus temperature for Haynes 188.

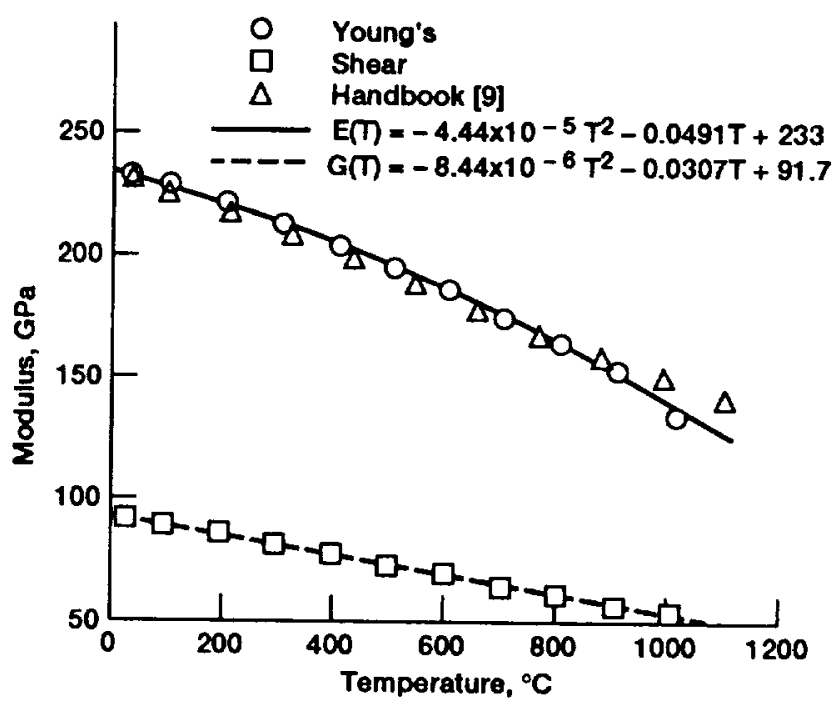

Figure 4.- Young's and shear moduli versus temperature for Haynes 188.

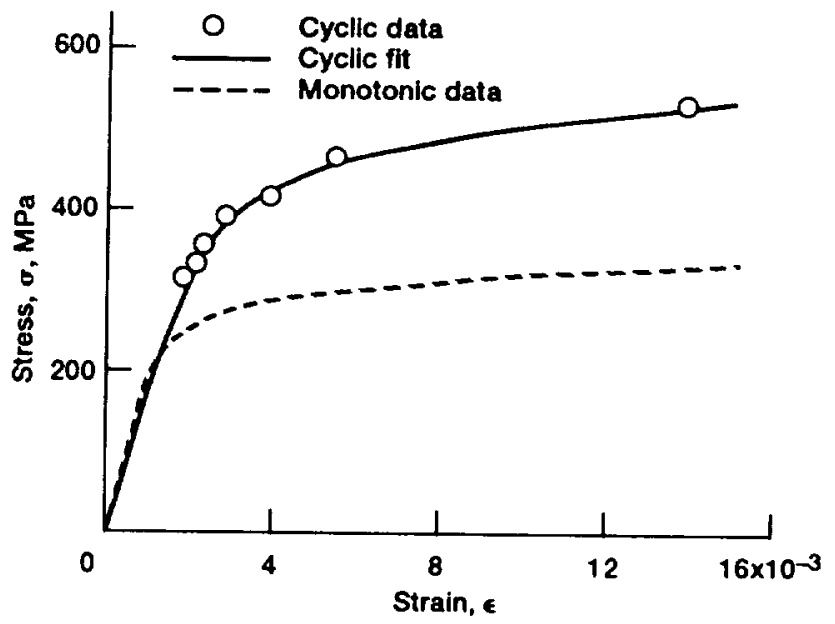

Figure 6.-Monotonic and cyclic axial stress-strain curves for Haynes 188 at $760^{\circ} \mathrm{C}$. 


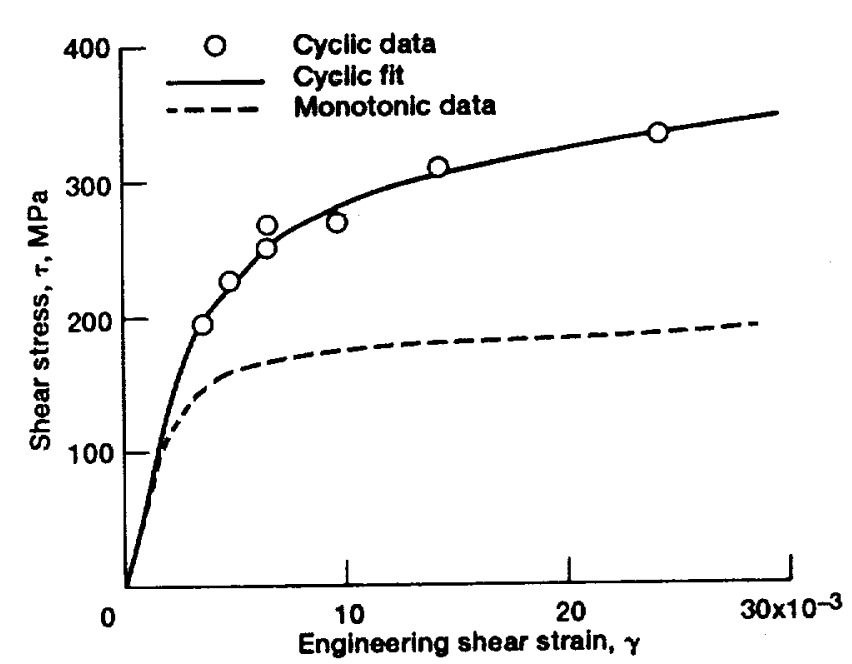

Figure 7.-Monotonic and cyclic engineering shear stressstrain curves for Haynes 188 at $760^{\circ} \mathrm{C}$.

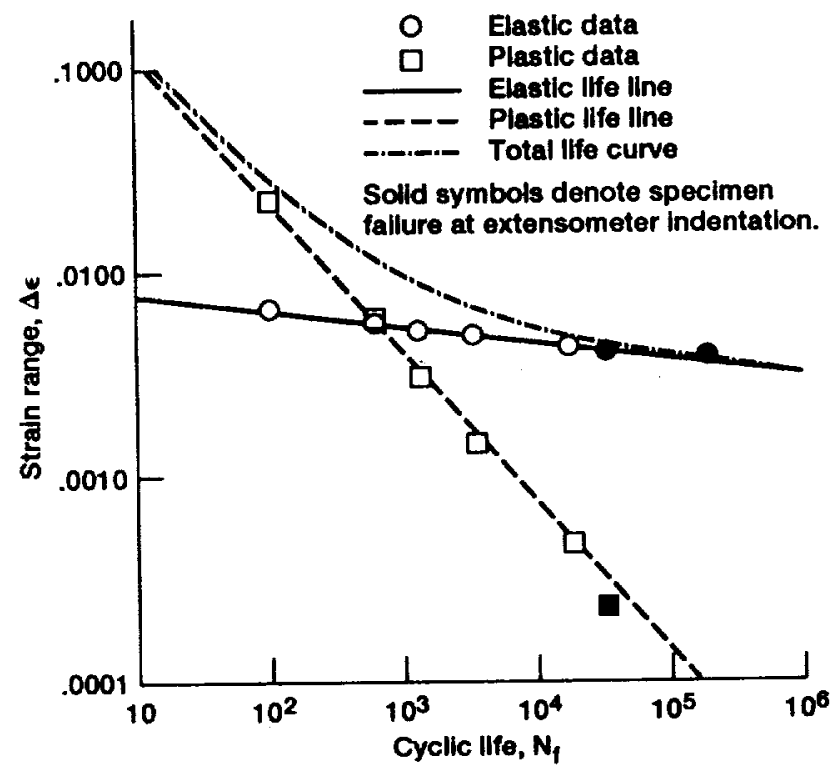

Figure 9.-Axlal fatigue life relations for Haynes 188 at $760^{\circ} \mathrm{C}$.

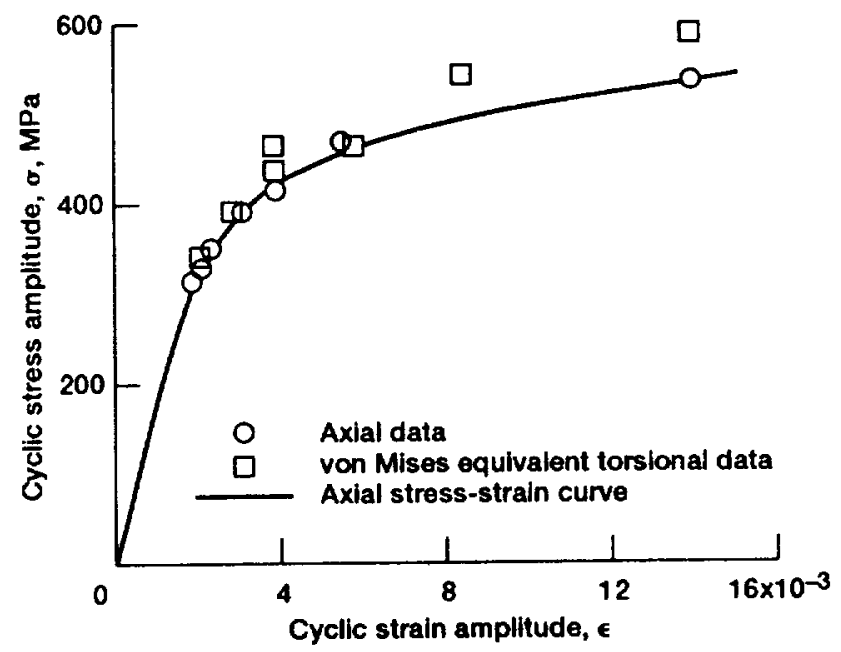

Figure 8.-Comparison of von Mises equivalent stress-strain data from torsional tests with axial stress-strain data.

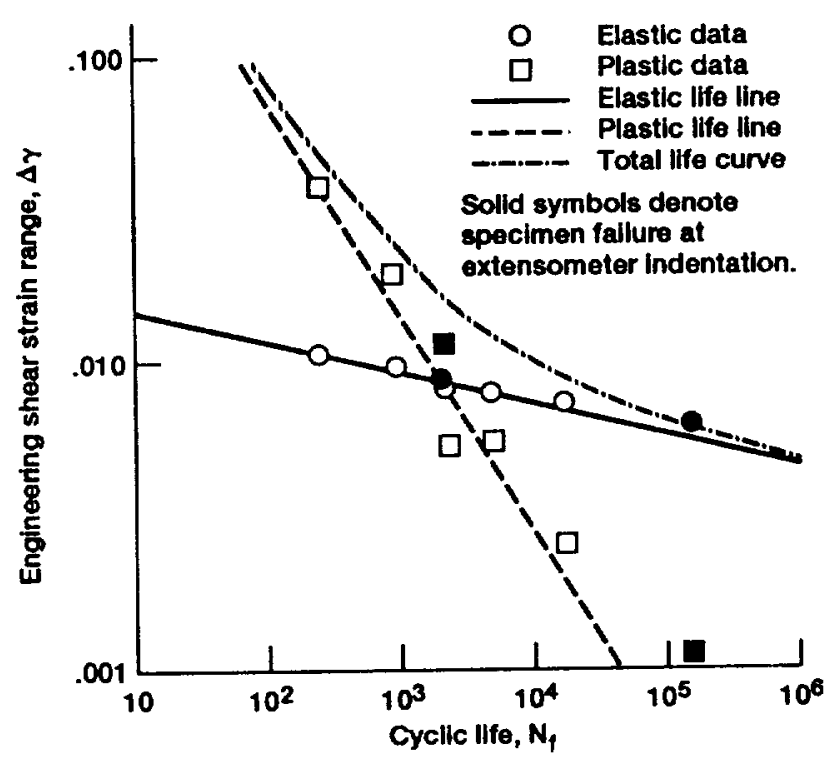

Figure 10.-Torsional fatigue life relations for Haynes 188 at $760^{\circ} \mathrm{C}$. 


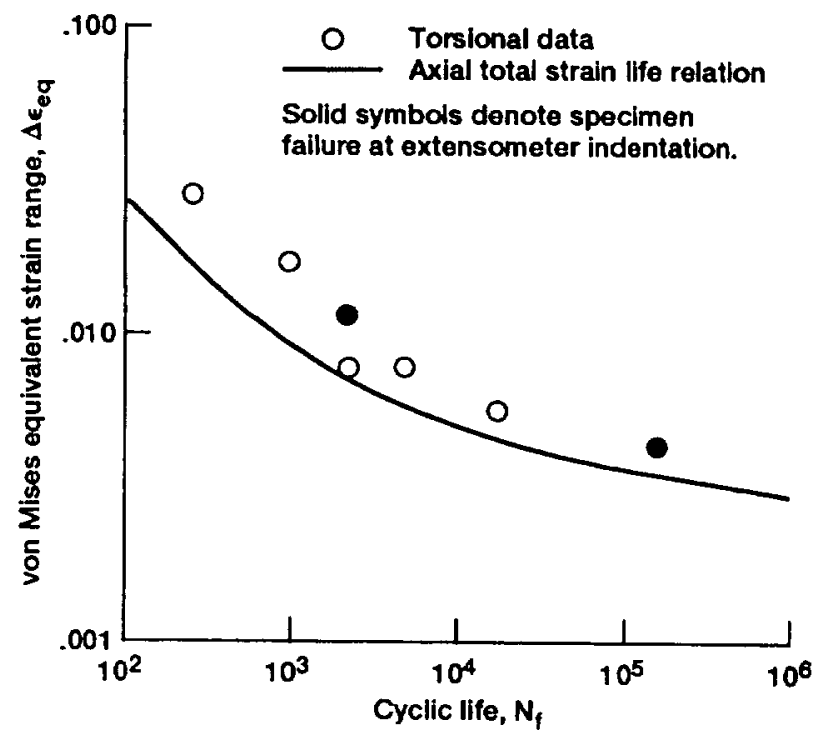

Figure 11. - Torsional fatigue life prediction by the von Mises equivalent straln range.

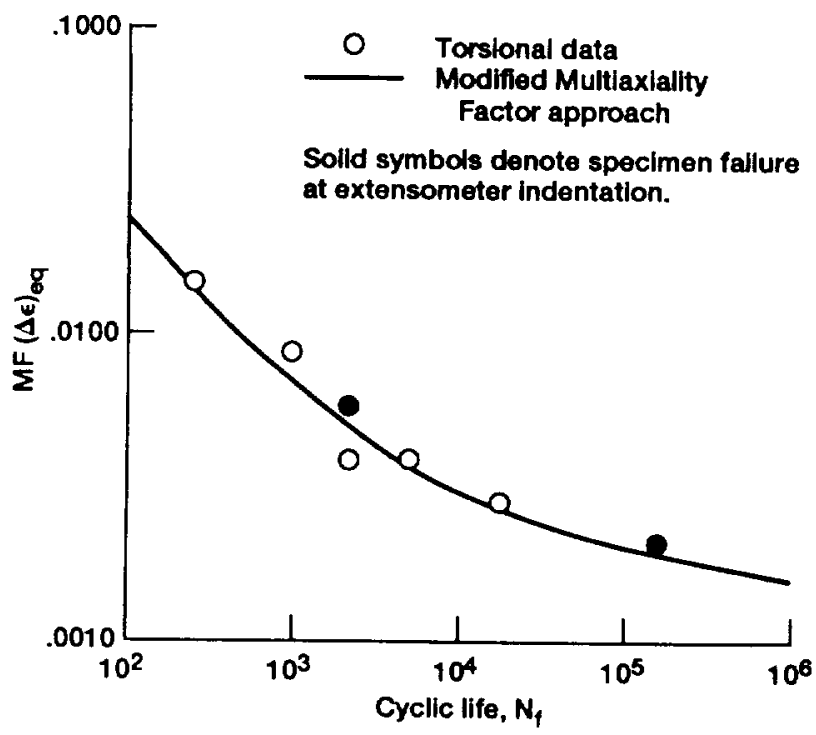

Figure 13.-Torsional fatigue life prediction by the Modified Multiaxiality Factor approach.

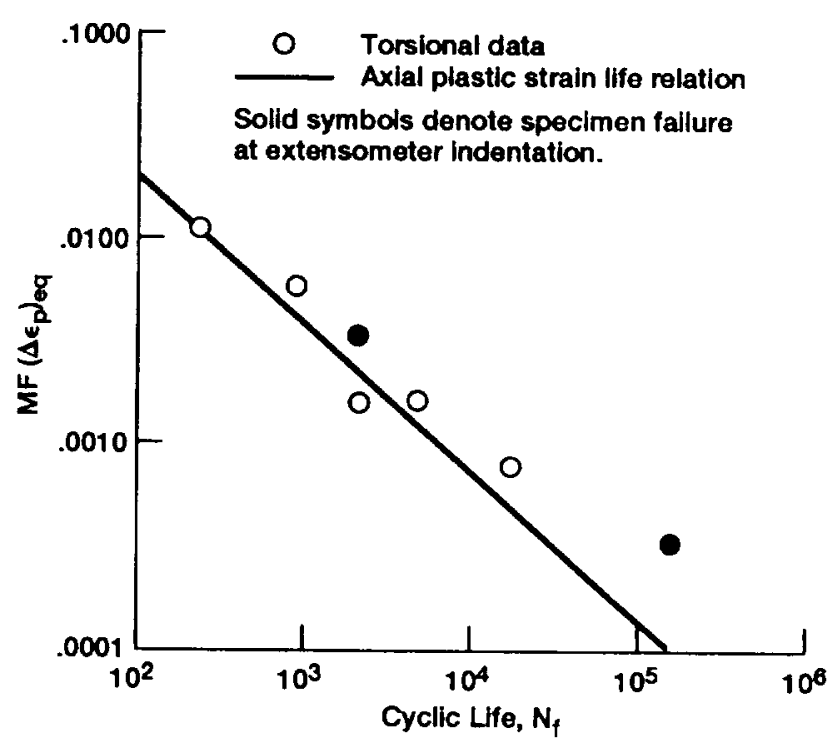

Figure 12.-Torsional fatigue life prediction by the MansonHalford parameter.

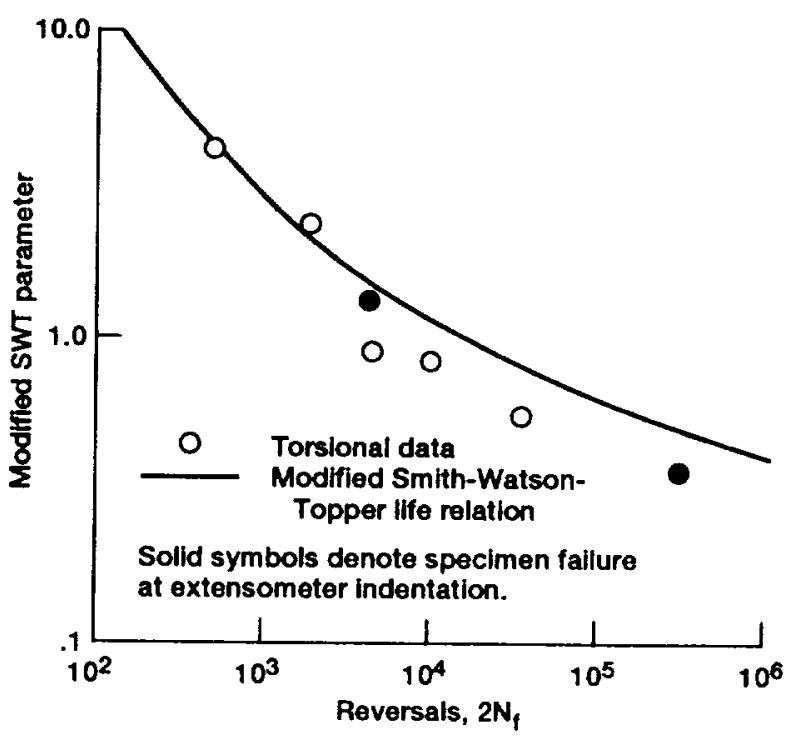

Figure 14.-Torsional fatigue life prediction by the Modified Smith-Watson-Topper parameter. 


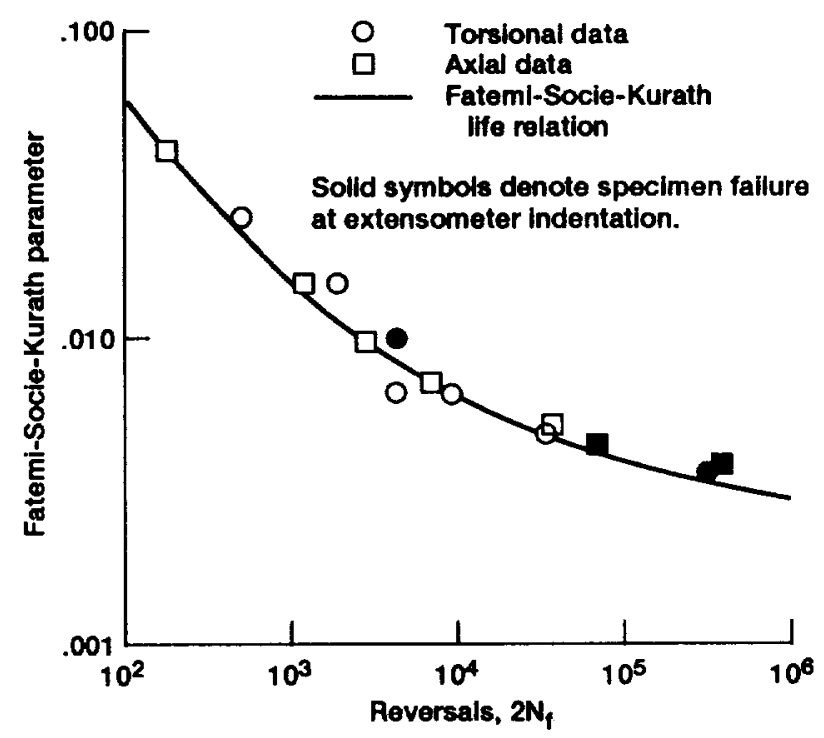

Figure 15.-Correlation of axial and torsional fatigue data by the Fatemi-Socie-Kurath parameter.

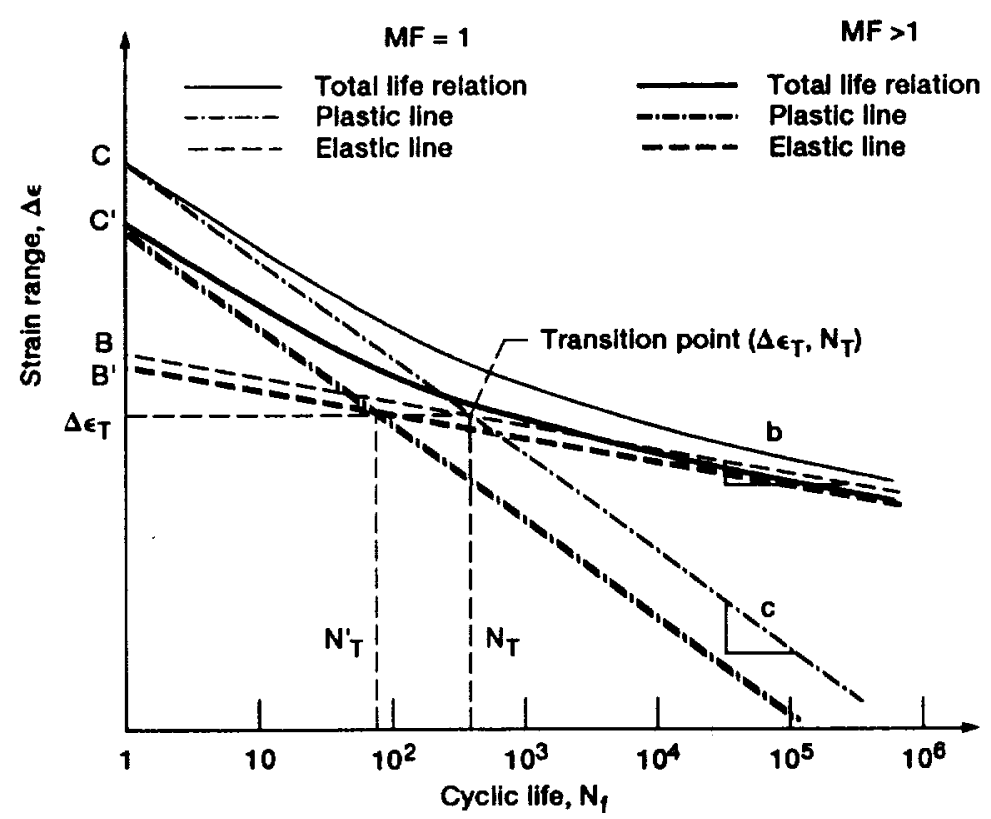

Figure 16.-Elastic, plastic, and total fatigue Iffe relations under unlaxial (MF = 1 ) and multiaxial (MF $>1$ ) conditions. 

Public reporting burden for this collection of information is estimated to average 1 hour per response, including the time for reviewing instructions, searching existing data sources, gathering and maintaining the data needed, and completing and reviewing the collection of information. Send comments regarding this burden estimate or any other aspect of this collection of information, including suggestions for reducing this burden. to Washington Headquarters Services, Directorate for intormation Operations and Reports, 1215 Jefferson Davis Highway. Suite 1204, Artington, VA 22202-4302, and to the Office of Management and Budget, Paperwork Reduction Project (0704-0188), Washington, DC 20503.

\begin{tabular}{l|l|l|} 
1. AGENCY USE ONLY (Leave blank) & 2. REPORT DATE & 3. REPORT TYPE AND DATES COVERED
\end{tabular}

\begin{tabular}{|l|l|l|}
\hline June 1992 & Technical Memorandum \\
\hline
\end{tabular}

\section{TITLE AND SUBTITLE}

Elevated Temperature Axial and Torsional Fatigue Behavior of Haynes 188

6. AUTHOR(S)

Peter J. Bonacuse and Sreeramesh Kalluri

\section{FUNDING NUMBERS}

WU-553-13-00
7. PERFORMING ORGANIZATION NAME(S) AND ADDRESS(ES)

NASA Lewis Rescarch Center

Cleveland, Ohio 44135-3191

and

Propulsion Directorate

U.S. Army Aviation Systems Command

Cleveland, Ohio 44135-3191
9. SPONSORING/MONITORING AGENCY NAMES(S) AND ADDRESS(ES)

National Acronautics and Space Administration

Washington, D.C. 20546-000)

and

U.S. Army Aviation Systems Command

St. Louis, Mo. 63120-1798
8. PERFORMING ORGANIZATION

REPORT NUMBER

E-6788

11. SUPPLEMENTARY NOTES

Peter J. Bonacuse, Propulsion Directorate, U.S. Army Aviation Systems Command; Sreeramesh Kalluri, Sverdrup Technology, Inc., Lewis Research Center Group, 2001 Aerospace Parkway, Brook Park, Ohio 44142. Responsible person, Peter J. Bonacuse, (216) 433-3309.

12a. DISTRIBUTION/AVAILABILITY STATEMENT 12b. DISTRIBUTION CODE

Unclassified - Unlimited

Subject Category 39

\section{ABSTRACT (Maximum 200 words)}

The results of high-temperature axial and torsional low-cycle fatigue experiments performed on Haynes 188 , a wrought cobalt-base superalloy, are reported. Fatigue tests were performed at $760^{\circ} \mathrm{C}$ in air on thin-walled tubular specimens at various strain ranges and under strain control. Data are also presented for coefficient of thermal expansion, elastic modulus, and shear modulus at various temperatures from room to $1000{ }^{\circ} \mathrm{C}$, and monotonic and cyclic stress-strain curves in tension and in shear at $760^{\circ} \mathrm{C}$. This data set is used to evaluate several multiaxial fatigue life models (most were originally developed for room temperature multiaxial life prediction) including von Mises equivalent strain range (ASME boiler and pressure vessel code), Manson-Halford, Modified Multiaxiality Factor (proposed in this paper), Modified Smith-Watson-Topper, and Fatemi-Socie-Kurath. At von Mises equivalent strain ranges (the torsional strain range divided by $\sqrt{3}$, taking the Poisson's ratio to be 0.5 ), torsionally strained specimens lasted, on average, factors of 2 to 3 times longer than axially strained specimens. The Modified Multiaxiality Factor approach shows promise as a useful method of estimating torsional fatigue life from axial fatigue data at high temperatures. Several difficulties arose with the specimen geometry and extensometry used in these experiments. Cracking at extensometer probe indentations was a problem at smaller strain ranges. Also, as the largest axial and torsional strain range fatigue tests neared completion, a small amount of specimen buckling was observed.

\section{SUBJECT TERMS}

Axial fatigue; Torsional fatigue; Stress-strain curves; Cobalt-base superalloy; Elevated temperature; Life prediction

\begin{tabular}{|c|c|}
\hline $\begin{array}{c}\text { 17. SECURITY CLASSIFICATION } \\
\text { OF REPORT } \\
\text { Unclassified }\end{array}$ & $\begin{array}{c}\text { 18. SECURITY CLASSIFICATION } \\
\text { OF THIS PAGE } \\
\text { Unclassified }\end{array}$ \\
\hline
\end{tabular}

19. SECURITY CLASSIFICATION OF ABSTRACT

Unclassified 